\title{
Preface: First European cyclodextrin conference
}

\author{
Kim Lambertsen Larsen • Thorsteinn Loftsson • \\ Antonino Mazzaglia $\cdot$ Pekka Jarho
}

Received: 5 January 2011 / Accepted: 5 January 2011

(C) Springer Science+Business Media B.V. 2011

This special issue of Journal of Inclusion Phenomena and Macrocyclic Chemistry contains selected full papers from invited lectures, oral and poster presentations presented at the First European Cyclodextrin Conference held in Aalborg, Denmark from 11th to 13th of October 2009.

This was the first conference in a biennial series of conferences organized under the auspices of the newly formed European Cyclodextrin Society. The aim of the meeting series is to provide an european platform for the enhancement of the scientific knowledge on cyclodextrins and to promote exploitation of their unique properties in various applications. We wish to encourage interaction and collaboration between scientists from all fields of academia and industry.

We wish to thank all presenters for their invaluable contribution to the success of the conference and for making the event stimulating and enjoyable. Additionally, we wish to thank our sponsors for their financial support and the scientific advisors for their encouragement and valuable contributions.

The Second European Cyclodextrin Conference will be held October 2nd through October 4th 2011 in Asti, Italy, organized by Professor Francesco Trotta, University of Turin. We hope to see you again in Italy.
K. L. Larsen ( $₫)$

Department of Biotechnology, Chemistry and Environmental

Engineering, Aalborg University, Sohngaardsholmsvej 57,

9000 Aalborg, Denmark

e-mail: kll@bio.aau.dk

T. Loftsson

Department of Pharmacy, University of Iceland,

Hofsvallagata 53, 107 Reykjavik, Iceland

A. Mazzaglia

ISMN-CNR, c/o Dipartimento di Chimica Inorganica,

Chimica Analitica e Chimica Fisica, University of Messina,

Salita Sperone 31, 98166 Messina, Italy

P. Jarho

Department of Pharmaceutical Chemistry,

University of Kuopio, 70211 Kuopio, Finland 